\title{
A dynamical system approach to soil salinity and sodicity
}

\author{
Yair $\mathrm{Mau}^{\mathrm{a}}$, Amilcare Porporato $^{\mathrm{a}}$ \\ ${ }^{a}$ Department of Civil and Environmental Engineering, Duke University, Durham, North Carolina, USA
}

\begin{abstract}
Soil salinity and sodicity impose severe constrains to agriculture, especially in arid and semi-arid regions, where goodquality water for irrigation is scarce. While detailed models have been proposed in the past to describe the dynamics of salt and sodium in the soil, they typically require cumbersome calculations and are not amenable to theoretical analysis. Here we present an analytical model for the dynamics of salinity and sodicity in the root zone. We determine the dependence of steady-state salinity and sodicity levels on irrigation water quality and derive the trajectories in the phase space. The only stationary solution the equations admit is a stable node. Through numerical integration and analysis of the eigenvalues of the derived two-dimensional system of equations, the slower time scale associated with sodification is quantified with respect to the faster time scale associated to salinization. The role of different cation exchange equations (Gapon and Vanselow conventions) are shown to be practically the same with regard to the phase-space dynamics and the time scales. The results can be applied in controlling for low levels of salinity and sodicity, and in planning remediation strategies that are timely and economical.
\end{abstract}

Keywords: salinity, sodicity, irrigation, exchange reactions

\section{Introduction}

Soil salinity and sodicity impose stress on agricultural crops, reducing yields when critical thresholds are surpassed $[1,2]$. While soil salinity refers to high concentrations of salt in the soil, soil sodicity is the condition in which sodium constitutes a large portion of overall cations, not necessarily accompanied by high salinity levels. Increased osmotic pressure of the soil water, which impedes its uptake by the roots, and nutrient imbalances, which in turn lead to toxicities and deficiencies, are the major causes for the adverse effects of salinity and sodicity on plant growth [3]. Other detrimental factors include poor physical soil conditions, like low permeability to air and water, caused by clay swelling and dispersion, associated with a complex interplay between sodicity and electrolyte concentration [4].

Irrigation with poor-quality water and insufficient leaching of soils are major factors contributing to secondary salinization, or the accumulation of salt in soils by means of human intervention. Ghassemi et al. [5] estimated that about $20 \%$ of irrigated land are salt-affected, and nearly four million acres of farmland are lost to excessive salt every year $[6]$.

Detailed numerical models have been proposed to simulate the dynamics of water and salt in the root zone [7, 8]. However, they demand solving Richards' equation for the water flow and partial differential equations for the transport of chemical species. Thus, while being very detailed,

Email addresses: yairmau@gmail.com (Yair Mau), amilcare@duke.edu (Amilcare Porporato) they require cumbersome calculations if long-term predictions are required, and the lack of analytical solutions somewhat masks the relationships among governing variables. As a result, other simple approaches have been proposed: some analytical models are based on a balance equation for the soil salt with a stochastic term for rain induced leaching events $[9,10]$, but do not model explicitly soil water nor sodium; another account solves balance equations of water and salt cations (sodium and calcium) [11], but its solutions are strictly numerical. Partly with the exception of the latter, these simple models do not analyze in detail the interplay between cations in the soil complex and the solution, as well as the nonlinear dynamics resulting from the thermodynamic equilibrium of differently charged cations (e.g., $\mathrm{Na}^{+}$and $\mathrm{Ca}^{2+}$ ).

To investigate such dynamics, in this paper we present a simple analytical model of salinity and sodicity based on the balance equations for soil water and salt (sodium and calcium cations), coupled to an equation for their chemical thermodynamic equilibrium. In deterministic conditions (i.e., no stochastic forcing), these equations are amenable to analysis. We derive here the trajectories in phase space, the time scales for the dynamics, and the dependence of steady-state salinity and sodicity levels on irrigation water quality. We also discuss alternative choices of cation exchange equations, and their effects on phase-space dynamics.

The paper is structured as follows. Section 2 develops a dynamical equation for salt concentration in soil water, Section 3 then develops a dynamical equation for the fraction of sodium adsorbed in the soil, and Section 4 investi- 
Table 1: Definition of all symbols used throughout this paper.

\begin{tabular}{|c|c|c|}
\hline Symbol & Units & Description \\
\hline$C$ & $\mathrm{mmol}_{\mathrm{c}} / \mathrm{L}$ & electrolyte concentration \\
\hline $\mathrm{CEC}$ & $\mathrm{mmol}_{\mathrm{c}} / \mathrm{kg}$ & cation exchange capacity \\
\hline$E$ & - & equivalent fraction \\
\hline ESP & - & exchangeable sodium \% \\
\hline ESR & - & $\begin{array}{l}\text { exchangeable sodium } \\
\text { ratio }\end{array}$ \\
\hline$E T$ & $\mathrm{~mm} / \mathrm{d}$ & evapotranspiration rate \\
\hline$I$ & $\mathrm{~mm} / \mathrm{d}$ & irrigation rate \\
\hline$J$ & $\mathrm{mmol}_{\mathrm{c}} / \mathrm{m}^{2} / \mathrm{d}$ & salt flux \\
\hline$K_{g}$ & $\left(\mathrm{mmol}_{\mathrm{c}} / \mathrm{L}\right)^{-1 / 2}$ & $\begin{array}{l}\text { Gapon selectivity } \\
\text { coefficient }\end{array}$ \\
\hline$K_{s}$ & $\mathrm{~L} / \mathrm{d}$ & $\begin{array}{l}\text { saturated hydraulic } \\
\text { conductivity }\end{array}$ \\
\hline$K_{v}$ & $\left(\mathrm{mmol}_{\mathrm{c}} / \mathrm{L}\right)^{-1 / 2}$ & $\begin{array}{l}\text { Vanselow selectivity } \\
\text { coefficient }\end{array}$ \\
\hline $\mathrm{LF}$ & - & leaching fraction \\
\hline$M$ & $\mathrm{~kg} / \mathrm{m}^{2}$ & dry soil mass \\
\hline$n$ & - & soil porosity \\
\hline$q$ & $\mathrm{mmol}_{\mathrm{c}} / \mathrm{m}^{2}$ & salt content \\
\hline$s$ & - & relative soil moisture \\
\hline$S^{\star}$ & $\left(\mathrm{mmol}_{\mathrm{c}} / \mathrm{L},-\right)$ & stationary solution \\
\hline SAR & $\left(\mathrm{mmol}_{\mathrm{c}} / \mathrm{L}\right)^{1 / 2}$ & sodium adsorption ratio \\
\hline$w$ & $\mathrm{~L} / \mathrm{m}^{2}$ & volumetric soil water \\
\hline$x$ & - & normalized distance \\
\hline$Z_{r}$ & $\mathrm{~mm}$ & rooting depth \\
\hline$i$ subscript & - & irrigation water \\
\hline$s$ subscript & - & soil water \\
\hline$x$ subscript & - & exchange complex \\
\hline$\star$ superscript & - & steady state \\
\hline 0 subscript & - & initial condition \\
\hline
\end{tabular}

gates the coupled dynamics of the sodium fraction and the salt concentration in phase space. Finally, we synthesize our results and present conclusions in Section 5. Table 1 shows the definition of all symbols defined throughout this paper.

\section{Coupled dynamics of water and salt balances}

\subsection{Soil water balance}

We begin by considering the water and salt balances in a unit area of soil subject to irrigation. The balance equation for the relative soil moisture $s$ is [12]

$$
n Z_{r} \frac{\mathrm{d} s}{\mathrm{~d} t}=P(t)+I(t)-E T(s)-L(s)-Q(s),
$$

where $Z_{r}$ is the rooting soil depth and $n$ is the dimensionless porosity. The water inputs are the precipitation $P$ and irrigation $I$, while water leaves the system through evapotranspiration $E T$, deep percolation $L$ and surface runoff $Q$. For simplicity, the water table is considered to be deep with respect to the rooting zone, so the balance equation (1) does not show a water upflow term. However, contributions from the ground water can be easily included, as was done by [11].

In this paper we focus on the nonlinear dynamics of water and salt, and the interactions between soil salinity and sodicity levels. For simplicity we concentrate on the deterministic system governing such dynamics and therefore we exclude the temporal forcing. This can be conceptualized by considering a typical dry season in a semiarid or arid region (negligible precipitation compared to irrigation, $P=0$ ), where the relative soil moisture has achieved the steady state $s^{\star}$ under a constant irrigation rate $I$ and constant evapotranspiration rate $E T$. In a stress-avoidance irrigation method, $s^{\star}$ would be at the point of incipient stomatal closure, i.e., the relative soil moisture for which plant transpiration is reduced [13]. However, even a slight concentration of dissolved salts in irrigation water requires some amount of overirrigation in order to guarantee the leaching of salts from the root zone. As a result, $s^{\star}$ can be considered here to correspond to a value of soil moisture slightly above the so-called field capacity. With the above assumptions, surface runoff $Q$ can also be considered negligible, so that the balance Eq. (1) becomes

$$
L\left(s^{\star}\right)=I-E T \text {. }
$$

The percolation function is modeled by the simple function [14]

$$
L(s)=K_{s} \cdot s^{c},
$$

where the saturated hydraulic conductivity $K_{s}$ and the parameter $c$ in the equation above depend on the soil properties [12]. Solving Eqs. (2) and (3), the steady-state soil moisture is

$$
s^{\star}=\left(\frac{I-E T}{K_{s}}\right)^{1 / c} .
$$

In what follows we refer to the water volume per unit area $w^{\star}=n Z_{r} s^{\star}$. Note that when $Z_{r}$ is given in millimeters, the units of $w^{\star}$ are in $\mathrm{L} / \mathrm{m}^{2}$.

\subsection{Salt balance}

The salt content $q_{s}$ in the soil water is given by the number of moles of charge (or equivalents) of cations in a squared meter. The balance equation for $q_{s}$ is

$$
\frac{\mathrm{d} q_{s}}{\mathrm{~d} t}=J_{\mathrm{in}}-J_{\text {out }}
$$

where the input flux of salt $J_{\text {in }}$ to the system is through the irrigation water of concentration $C_{i}$ (in millimoles of charge per liter, or $\mathrm{mmol}_{\mathrm{c}} / \mathrm{L}$ ), while salt can leave the system through the percolation of soil water to lower soil depths, represented by the output flux $J_{\text {out }}$. These fluxes can be written as

$$
\begin{gathered}
J_{\text {in }}=I C_{i} \\
J_{\text {out }}=L^{\star} C,
\end{gathered}
$$


where $L^{\star}$ is shorthand for $L\left(s^{\star}\right)$, and $C=q_{s} / w^{\star}$ is the salt concentration (in $\mathrm{mmol}_{\mathrm{c}} / \mathrm{L}$ ), also called electrolyte concentration. Note that $\mathrm{mmol}_{\mathrm{c}} / \mathrm{L}$ translates into the SI unit $\mathrm{mol}_{\mathrm{c}} / \mathrm{m}^{3}$, without the need of any conversion factor. We emphasize that $q_{s}$ refers only to the salt dissolved in water; the salt bound to the soil particles will be discussed in Section 3.

Because of the assumption of no exfiltration from the aquifer to the rooting zone, we rule out an interesting feedback of salt transport between these two regions, mediated by percolation and exfiltration. For an account on this phenomenon, see [11]. A constant rate of salt dry deposition influx $J_{\text {dry }}$ can be incorporated into the model, by simply changing the salt input flux (6a) to $J_{\text {in }}=I C_{i}+J_{\text {dry }}$.

Dividing Eq. (5) by $w^{\star}$, an equation for the salt concentration $C$ is easily obtained as

$$
\frac{\mathrm{d} C}{\mathrm{~d} t}=\frac{I C_{i}}{w^{\star}}-\frac{L^{\star}}{w^{\star}} C .
$$

This linear ordinary differential equation is the main equation of this section. It describes the evolution of soil salinity, once the input of salt from irrigation and the rates of irrigation and percolation have been determined.

Assuming constant irrigation parameters $I$ and $C_{i}$, Eq. (7) can be solved as

$$
C(t)=C^{\star}+\left(C_{0}-C^{\star}\right) e^{-\frac{t}{\tau_{C}}},
$$

where

$$
C^{\star}=\frac{C_{i}}{L^{\star} / I} \quad \tau_{C}=\frac{w^{\star}}{L^{\star}},
$$

$C_{0}$ is the concentration at $t=0$, and $\tau_{C}$ is the typical time scale of convergence to the equilibrium solution. The quantity $L^{\star} / I$ is the portion of irrigation water that infiltrates past the root zone, and it is called leaching fraction (LF) [2], so we can rewrite the steady-state concentration as $C^{\star}=C_{i} / \mathrm{LF}$. Clearly $\mathrm{LF} \leqslant 1$, which means that $C^{\star} \geqslant C_{i}$.

Figure 1(a) shows the evolution of the soil water concentration for various values of irrigation rate, illustrating the role of LF on the steady-state concentration level $C^{\star}$ and on the typical time scale $\tau_{C}$. Figure 1(b) shows the steady-state concentration $C^{\star}$ in the parameter space (LF, $C_{i}$ ), where the divisions depict the qualitative thresholds proposed by Maas [1] to classify a plant's salt tolerance. As expected, higher leaching fraction values (that translate into higher irrigation rates) result in decreased steady-state salinity levels. The dashed line indicates the leaching requirement [15] curve for moderately sensitive crops, i.e., it shows the minimal values of the leaching fraction needed in order to maintain salinity levels suitable for this kind of crops.

According to Eq. (9), as long as the leaching of salts is adequate, one can make use of saline water for irrigation without risking crossing a critical threshold of soil water salinity. The more saline the irrigation water, the higher
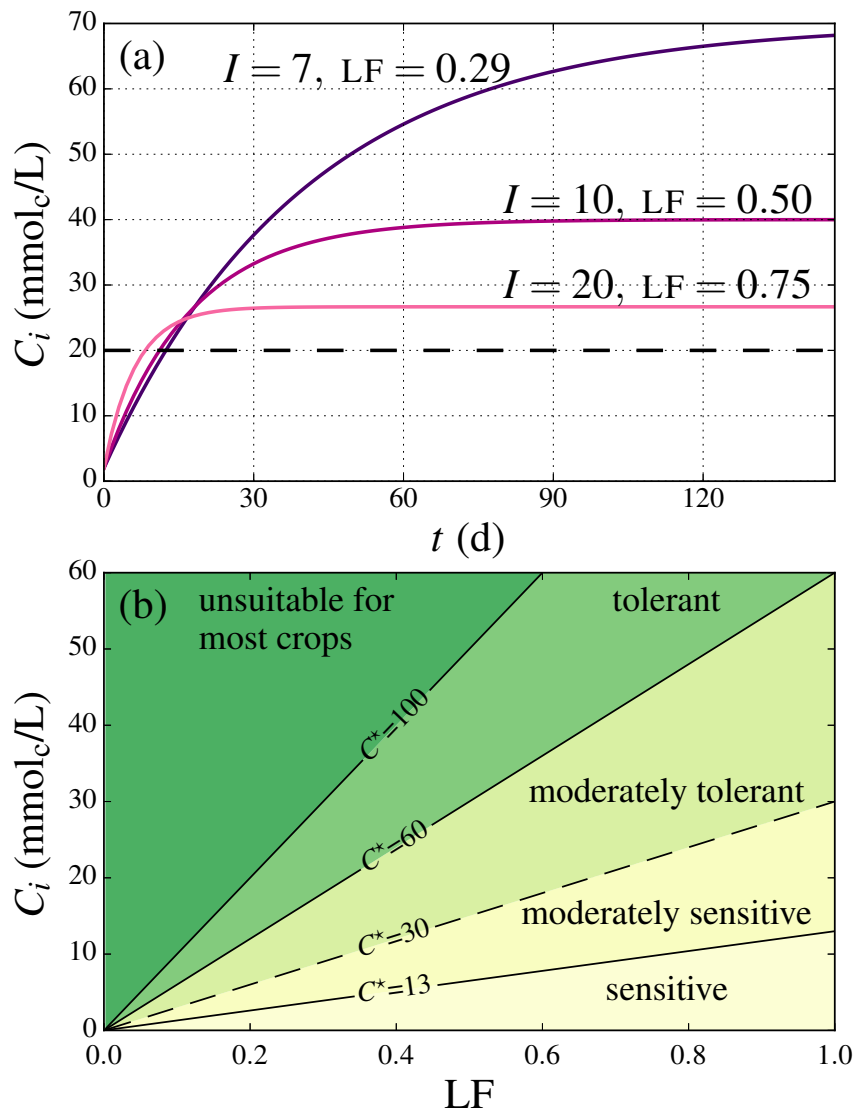

Figure 1: Panel (a): Evolution of soil water concentration for various values of irrigation rate $I$ (in $\mathrm{mm} / \mathrm{d})$, with $C_{0}=2 \mathrm{mmol}_{\mathrm{c}} / \mathrm{L}$ and $C_{i}=20 \mathrm{mmol}_{\mathrm{c}} / \mathrm{L}$. Panel (b): Steady-state salinity $C^{\star}\left(\mathrm{mmol}_{\mathrm{c}} / \mathrm{L}\right)$ in the parameter space $\left(\mathrm{LF}, C_{i}\right)$. Parameters: $n=0.43, Z_{r}=300$ $\mathrm{mm}, c=12.8, K_{s}=800 \mathrm{~mm} / \mathrm{d}, E T=5 \mathrm{~mm} / \mathrm{d}$.

the leaching fraction has to be in order to curb salt concentration below critical values. Furthermore, a relative low percolation rate $L$ means not only that the steady-state concentration will be high, but also that the salt accumulation process will be slow, as described by the typical time scale $\tau_{C}$.

A specific electrical conductance $\kappa$ (or simply electrical conductivity) of $4 \mathrm{dS} / \mathrm{m}$ of a saturated soil extract is a commonly accepted threshold above which a soil is defined as saline [15]. This threshold is converted to $C=40$ $\mathrm{mmol}_{\mathrm{c}} / \mathrm{L}$ in this paper, according to the common rule of thumb $C\left[\mathrm{mmol}_{\mathrm{c}} / \mathrm{L}\right]=10 \kappa[\mathrm{dS} / \mathrm{m}]$.

We will now study the salt cation composition and the role of irrigation water quality on the processes of salinization and sodification of soils.

\section{Sodicity dynamics}

Having described how the total salinity evolves via Eq. (8), the next step is to describe the partitioning between the cations in the soil solution and in the adsorbed phase, as a function of the properties of the soil solution and thus of the quality of irrigation water. 
The main cations found in saline soils are $\mathrm{Na}^{+}, \mathrm{Ca}^{2+}$, $2 \mathrm{Mg}^{2+}$, and, to a lesser degree, $\mathrm{K}^{+}$. All of them are in3 volved in an intricate dynamical process of adsorption and 4 desorption, whose mathematical modeling would be too 5 cumbersome to our efforts of working with a simple model 6 for soil salinity and sodicity. In order to be able to proceed 7 analytically, we will assume that $\mathrm{Na}^{+}$and $\mathrm{Ca}^{2+}$ are the 8 only cations making up the salt content. The exchange 9 of $\mathrm{Na}^{+}$and $\mathrm{Ca}^{2+}$ is an epitome of binary exchange be-

$$
E_{s}^{\mathrm{Na}}=\frac{q_{s}^{\mathrm{Na}}}{q_{s}}, \quad E_{s}^{\mathrm{Ca}}=\frac{q_{s}^{\mathrm{Ca}}}{q_{s}},
$$

where, of course, $E_{s}^{\mathrm{Na}}+E_{s}^{\mathrm{Ca}}=1$. Using the equations above, and the already defined salt concentration in the soil water $C=q_{s} / w^{\star}$, the total charge of $\mathrm{Na}^{+}$and $\mathrm{Ca}^{2+}$ in the soil water can be written as

$$
\begin{aligned}
q_{s}^{\mathrm{Na}} & =C w^{\star} E_{s}^{\mathrm{Na}} \\
q_{s}^{\mathrm{Ca}} & =C w^{\star} E_{s}^{\mathrm{Ca}} .
\end{aligned}
$$

Besides being dissolved in soil water, the sodium and calcium cations can be adsorbed on soil particles, whose surfaces have negative charge. The adsorbed cations can be replaced by cations in the soil water solution, and therefore are called readily exchangeable cations. Together with the soil particles they constitute the exchange complex. The Cation Exchange Capacity (CEC) is a measure of the maximum quantity of adsorbed cation charge in a unit mass of soil [16], and can be written as the sum

$$
\mathrm{CEC}=\frac{q_{x}}{M}=\frac{q_{x}^{\mathrm{Na}}+q_{x}^{\mathrm{Ca}}}{M},
$$

where the subscript $x$ denotes cations in the exchange complex, and $M$ is the mass of dry soil in a unit area of depth $Z_{r}$. Using the same concept of equivalent fractions as in Eq. (11), we can write for the salt quantities in the exchange complex (in $\mathrm{mmol}_{\mathrm{c}} / \mathrm{m}^{2}$ )

$$
\begin{aligned}
& q_{x}^{\mathrm{Na}}=\mathrm{CEC} \cdot M \cdot E_{x}^{\mathrm{Na}} \\
& q_{x}^{\mathrm{Ca}}=\mathrm{CEC} \cdot M \cdot E_{x}^{\mathrm{Ca}} .
\end{aligned}
$$

The equivalent fraction of sodium in the exchange complex $E_{x}^{\mathrm{Na}}$, when expressed as a percentage, is commonly known as the Exchangeable Sodium Percentage (ESP). Different levels of sodicity hazard can be defined for various ranges of ESP [2]: None or slight $(\mathrm{ESP}<15 \%)$; light to moderate $(15 \%<\mathrm{ESP}<30 \%)$; moderate to high $(30 \%<$ ESP $<50 \%)$; high to very high $(50 \%<$ ESP $<70 \%)$; and extremely high $(\mathrm{ESP}>70 \%)$. Throughout this paper, by sodicity level we mean the equivalent fraction of sodium $E^{\mathrm{Na}}$ in the various phases (soil water, irrigation water and exchange complex).

\subsection{The Exchange Isotherm}

In order to model the dynamics of sodium in the soil we need a means to describe the replacement of one readily exchangeable cation by another cation in the soil water. Adsorption reactions of readily exchangeable cations have typical time scales of minutes to hours $[17,16]$, while, as it will be shown, the accumulation or depletion of sodium in the soil have a typical time scale of weeks to months. Because of these widely different time scales, we will consider the chemical balance between soil water and exchange complex to be practically instantaneous, and therefore the cations will be assumed to be in thermodynamic equilibrium at any given time.

Such an equilibrium is described by an exchange isotherm, i.e., an equation of the kind

$$
E_{s}^{\mathrm{Na}}=g_{s}\left(C, E_{x}^{\mathrm{Na}}\right),
$$

that relates the equivalent fraction of sodium in the soil water with that in the exchange complex, at a fixed temperature and pressure, and in equilibrium conditions [18, 16]. The exchange isotherm can be obtained from the Gapon equation [19], widely used in the study of soil salinization,

$$
\mathrm{ESR}=K_{g} \mathrm{SAR}
$$

where, $K_{g}$ is the Gapon selectivity coefficient, and the Exchangeable Sodium Ratio (ESR) and the Sodium Adsorption Ratio (SAR) are defined as

$$
\begin{aligned}
\mathrm{ESR} & =\frac{E_{x}^{\mathrm{Na}}}{E_{x}^{\mathrm{Ca}}}=\frac{\mathrm{ESP} / 100}{1-\mathrm{ESP} / 100} \\
\mathrm{SAR} & =\frac{[\mathrm{Na}]}{\sqrt{\frac{[\mathrm{Ca}]+[\mathrm{Mg}]}{2}}},
\end{aligned}
$$

in which the square brackets denote cation concentration in the soil water, in millimoles of charge per liter. Implicit in the definition of the SAR, in Eq. (17b), is that calcium gard to cation exchange [20]. This justifies our approach of $[\mathrm{Ca}]+[\mathrm{Mg}]$ in Eq. (17b) is substituted simply by [Ca].

The linear relation between ESR and SAR was established empirically for the range $0<$ SAR $<25$ by the and magnesium are chemically indistinguishable with regrouping both cations, and the sum of the concentrations 
United States Salinity Laboratory [15], with the Gapon selectivity coefficient given by $K_{g}=0.01475\left(\mathrm{mmol}_{\mathrm{c}} / \mathrm{L}\right)^{-1 / 2}$. This value for $K_{g}$ represents a mean behavior of 59 soil samples of varied origins ${ }^{1}$. Note, however, that exchange properties vary considerably between soils. For example, the experimental determination of $K_{g}$ for five soil types $[21,22]$ found it to range between 0.00866 and 0.01740 $\left(\mathrm{mmol}_{\mathrm{c}} / \mathrm{L}\right)^{-1 / 2}$.

Appendix A combines Eqs. (17) and (16) in order to derive the sought exchange isotherm

$$
\begin{aligned}
E_{x}^{\mathrm{Na}} & =g_{x}\left(C, E_{s}^{\mathrm{Na}}\right) \\
& =\left(1+\sqrt{\frac{1-E_{s}^{\mathrm{Na}}}{2 C}} \frac{1}{K_{g} E_{s}^{\mathrm{Na}}}\right)^{-1},
\end{aligned}
$$

which describes the dependence of $E_{x}^{\mathrm{Na}}$ on $E_{s}^{\mathrm{Na}}$ and $C$.

The inverse function of Eq. (18) will also be useful in the next subsection,

$$
\begin{aligned}
E_{s}^{\mathrm{Na}} & =g_{s}\left(C, E_{x}^{\mathrm{Na}}\right) \\
& =\frac{2}{1+\sqrt{1+8 K_{g}^{2} C\left(\frac{1}{E_{x}^{\mathrm{Na}}}-1\right)^{2}}} .
\end{aligned}
$$

Note that there are alternative descriptions of the cation exchange reaction of $\mathrm{Na}^{+}$and $\mathrm{Ca}^{2+}$ (see [16], Eq. (9.14)), and each interpretation of the process yields different versions of the exchange isotherm. Appendix B shows the detailed derivation of exchange reaction equations based on the "Vanselow convention", in contrast with the "Gapon convention".

In the next subsection we will base the derivation of a dynamical equation for soil sodicity on the Gapon exchange isotherm.

\subsection{Sodicity equation}

We will derive now an equation to describe the dynamics of the equivalent fraction $E_{x}^{\mathrm{Na}}$, that, together with Eq. (7) for the concentration, will constitute the coupled equations for soil salinity and sodicity.

The balance equation of total sodium in the soil is

$$
\frac{\mathrm{d} q^{\mathrm{Na}}}{\mathrm{d} t}=J_{\mathrm{in}}^{\mathrm{Na}}-J_{\mathrm{out}}^{\mathrm{Na}} .
$$

The input flux $J_{\text {in }}^{\mathrm{Na}}$ of sodium to the soil water solution, due only to irrigation, reads

$$
J_{\text {in }}^{\mathrm{Na}}=J_{\text {in }} E_{i}^{\mathrm{Na}}=C_{i} I E_{i}^{\mathrm{Na}},
$$

where $E_{i}^{\mathrm{Na}}$ is the equivalent fraction of sodium in the irrigation water. Conversely, the output flux $J_{\text {out }}^{\mathrm{Na}}$ of sodium

${ }^{1}$ Figure 9 in $[15$, p. 27$]$ reports a linear relation with a slight vertical offset: ESR $=-0.0126+0.01475$ SAR. However, it seems that the vertical offset is wrong by a factor of approximately three, and this widely used relation should actually read as ESR $=-0.0425+$ 0.01475 SAR. from the soil water, due to percolation of the solution to deeper soil layers, reads

$$
J_{\text {out }}^{\mathrm{Na}}=J_{\text {out }} E_{s}^{\mathrm{Na}}=C L^{\star} E_{s}^{\mathrm{Na}} .
$$

Using the fact that the total sodium content in the soil $q^{\mathrm{Na}}$ is the sum of the sodium in the soil solution and in the exchange complex, Eq. (20) can be written as

$$
\frac{\mathrm{d} q_{s}^{\mathrm{Na}}}{\mathrm{d} t}+\frac{\mathrm{d} q_{x}^{\mathrm{Na}}}{\mathrm{d} t}=C_{i} I E_{i}^{\mathrm{Na}}-C L^{\star} E_{s}^{\mathrm{Na}}
$$

Substituting Eqs. (12a) and (14a) into Eq. (23) and using the chain rule, gives

$$
\begin{aligned}
w^{\star} C \frac{\mathrm{d} E_{s}^{\mathrm{Na}}}{\mathrm{d} t}+w^{\star} E_{s}^{\mathrm{Na}} \frac{\mathrm{d} C}{\mathrm{~d} t}+\operatorname{CEC} M \frac{\mathrm{d} E_{x}^{\mathrm{Na}}}{\mathrm{d} t}= \\
C_{i} I E_{i}^{\mathrm{Na}}-C L^{\star} E_{s}^{\mathrm{Na}} .
\end{aligned}
$$

The equation above has three dynamical variables: the total salt concentration in the soil water $C$, and the equivalent fractions $E_{s}^{\mathrm{Na}}$ and $E_{x}^{\mathrm{Na}}$. In order to reduce Eq. $(24)$ to only two variables, $E_{x}^{\mathrm{Na}}$ and $C$, we can use the derived function $E_{s}^{\mathrm{Na}}=g_{s}\left(C, E_{x}^{\mathrm{Na}}\right)$ shown in Eq. (19). Rearranging the terms, and calling $E_{x}^{\mathrm{Na}}$ as $E$, Eq. (24) becomes

$$
\frac{\mathrm{d} E}{\mathrm{~d} t}=\frac{F_{1}-F_{2}(C, E)-F_{3}(C)\left[F_{4}(C, E)+F_{5}(C, E)\right]}{F_{6}+F_{7}(C, E)},
$$

where

$$
\begin{aligned}
F_{1} & =I C_{i} E_{i} \\
F_{2}(C, E) & =L^{\star} C g_{s}(C, E) \\
F_{3}(C) & =\frac{\mathrm{d} C}{\mathrm{~d} t} \\
F_{4}(C, E) & =w^{\star} g_{s}(C, E) \\
F_{5}(C, E) & =w^{\star} C \frac{\partial g_{s}(C, E)}{\partial C} \\
F_{6} & =\operatorname{CEC} M \\
F_{7}(C, E) & =w^{\star} C \frac{\partial g_{s}(C, E)}{\partial E} .
\end{aligned}
$$

Note that $F_{3}(C)=\mathrm{d} C / \mathrm{d} t$ was already found in Eq. (7), while the partial derivatives of $g_{s}$ in $F_{5}$ and $F_{7}$ follow from Eq. (19),

$$
\begin{aligned}
& \frac{\partial g_{s}(C, E)}{\partial C}=-\frac{2(1-E)^{2} K_{g} g_{s}^{3}}{E^{2}\left(2-g_{s}\right)} \\
& \frac{\partial g_{s}(C, E)}{\partial E}=\frac{4 C(1-E) K_{g} g_{s}^{3}}{E^{3}\left(2-g_{s}\right)} .
\end{aligned}
$$

A Vanselow-based version of Eq. (25) can be achieved simply by substituting $g_{s}$ by $v_{s}$ [Eq. (B.9b)], and its partial derivatives Eqs. (B.10). In what follows, Eq. (25) is understood to be formed by the Gapon-based function $g_{s}$ unless specified otherwise. 


\section{Study of the dynamical system}

From Eqs. (1), (7), and (25) we have a dynamical system of three variables: soil moisture $s$, salt concentration in the soil water $C$, and equivalent fraction of sodium in the exchange complex $E$. However, assuming constant soil moisture, we are left with two dynamical equations only, for $C$ and $E$. This is justified by the fact that the soil moisture reaches its steady-state value $s^{\star}$ in a time scale of days, while salinization and sodification processes occur in the order of a few weeks to months.

This choice of conditions has two clear advantages. First, it leaves us to study the dynamics of a deterministic two-dimensional system of ordinary differential equations. This analysis highlights the one-way effect of the soil water salt concentratration $C$ on the dynamics of $E$, yielding typical sodification time scales easy to calculate (subsection 4.3).

The drawbacks of this choice are twofold. In case of time-varying irrigation and evapotranspiration rates, or when precipitation is present, the water content in the soil is obviously not fixed, and an additional dynamical equation for $s$ should is required to modulate $C$ and $E$. In addition, salinity and sodicity can themselves modulate the water dynamics in the soil by changing the infiltration rate and hydraulic conductivity [23, 24, 25]. These issues will be addressed in future research, where the three-variable system $s, C, E$ will be considered.

To sum up, eliminating the dynamic variable $s$, the equations (25) and (7) form the two-dimensional dynamical system

$$
\begin{aligned}
& \frac{\mathrm{d} C}{\mathrm{~d} t}=h_{1}(C) . \\
& \frac{\mathrm{d} E}{\mathrm{~d} t}=h_{2}(C, E)
\end{aligned}
$$

Note that any point $(C, E)$ in the phase space can be readily converted into the equivalent fractions $E_{x}^{\mathrm{Ca}}, E_{s}^{\mathrm{Na}}$ and $E_{s}^{\mathrm{Ca}}$ using the fact that $E^{\mathrm{Na}}+E^{\mathrm{Ca}}=1$, the Gapon Equation (A.2) and its solution Eq. (19).

\subsection{Stationary solution}

The system of equations (28) admits one stationary solution $S^{\star}=\left(C^{\star}, E^{\star}\right)$. $C^{\star}$ was already found in Eq. (9) as

$$
C^{\star}=\frac{C_{i}}{L^{\star} / I} .
$$

In order to find $E^{\star}$, we could solve $h_{2}\left(C^{\star}, E\right)=0$. However, a much easier task is to solve the balance Eq. (23) in steady-state conditions, where the time derivatives vanish and $C=C^{\star}$ :

$$
C_{i} I E_{i}^{\mathrm{Na}}=C^{\star} L^{\star}\left(E_{s}^{\mathrm{Na}}\right)^{\star} .
$$

Using Eq. (29), the steady-state equivalent fraction of sodium in the soil water then equals the equivalent fraction of sodium in the irrigation water, i.e. $\left(E_{s}^{\mathrm{Na}}\right)^{\star}=E_{i}^{\mathrm{Na}}$. In other words, the sodicity level of soil water equilibrates with that of irrigation water. Finally, using Eq. (18), one obtains

$$
\begin{aligned}
E^{\star} & =g_{x}\left(C^{\star},\left(E_{s}^{\mathrm{Na}}\right)^{\star}\right) \\
& =\left(1+\sqrt{\frac{L^{\star}\left(1-E_{i}^{\mathrm{Na}}\right)}{2 I C_{i}}} \frac{1}{K_{g} E_{i}^{\mathrm{Na}}}\right)^{-1} .
\end{aligned}
$$

The physical interpretation of the result above is that given the steady-state salinity $C^{\star}$ and the sodicity of the irrigation water $E_{i}^{\mathrm{Na}}$, one can calculate the steady-state soil sodicity $E^{\star}$ simply by using the exchange isotherm (18).

Fig. 2(a) shows $E^{\star}$ as a function of the irrigation parameters $C_{i}$ and $E_{i}^{\mathrm{Na}}$. The dashed lines indicate the sodicity hazard boundaries discussed in Section 3. For constant sodium fractions, higher irrigation water concentrations result in higher values of ESP, as suggested previously in Fig. A.5.

Fig. 2(b) shows the dependence of the sodicity hazard boundaries on irrigation rate. Higher irrigation rates translate into reduced sodicity hazard, for fixed $C_{i}$ and $E_{i}^{\mathrm{Na}}$.

Although there is no largely accepted definition of a sodic soil [4], in the following analysis we will use the value $E=0.15(\mathrm{ESP}=15 \%)$ to separate sodic from non-sodic soils [15].

\subsection{Linear stability analysis}

The linear stability of $S^{\star}$ is determined by the eigenvalues of the Jacobian of Eqs. (28), calculated at $S^{\star}$. The Jacobian reads

$$
J=\left(\begin{array}{cc}
\frac{\partial h_{1}}{\partial C} & 0 \\
\frac{\partial h_{2}}{\partial C} & \frac{\partial h_{2}}{\partial E}
\end{array}\right) .
$$

The null element in the Jacobian results from the fact that the dynamics of $C$ does not depend on $E$, as can be seen in Eq. (7). Therefore, the two eigenvalues $\sigma_{1}, \sigma_{2}$ are clearly the diagonal elements

$$
\sigma_{1}=\left.\frac{\partial h_{1}}{\partial C}\right|_{C^{\star}}, \quad \sigma_{2}=\left.\frac{\partial h_{2}}{\partial E}\right|_{S^{\star}} .
$$

The solution $S^{\star}$ will be linearly stable if the real part of both eigenvalues is negative. The first eigenvalue is always negative,

$$
\sigma_{1}=-\frac{L^{\star}}{w^{\star}}=-\frac{1}{\tau_{C}},
$$

while the analytical form of $\sigma_{2}$ is too cumbersome and will not be presented here. We could not determine analytically the region in the parameter space where $\sigma_{2}<0$, however, numerical simulations, together with the fact that $E$ is bounded $(0 \leqslant E \leqslant 1)$, suggest that $S^{\star}$ is in fact a stable fixed point (a stable node). Any oscillations are ruled out because $\sigma_{1}$ is real valued. 


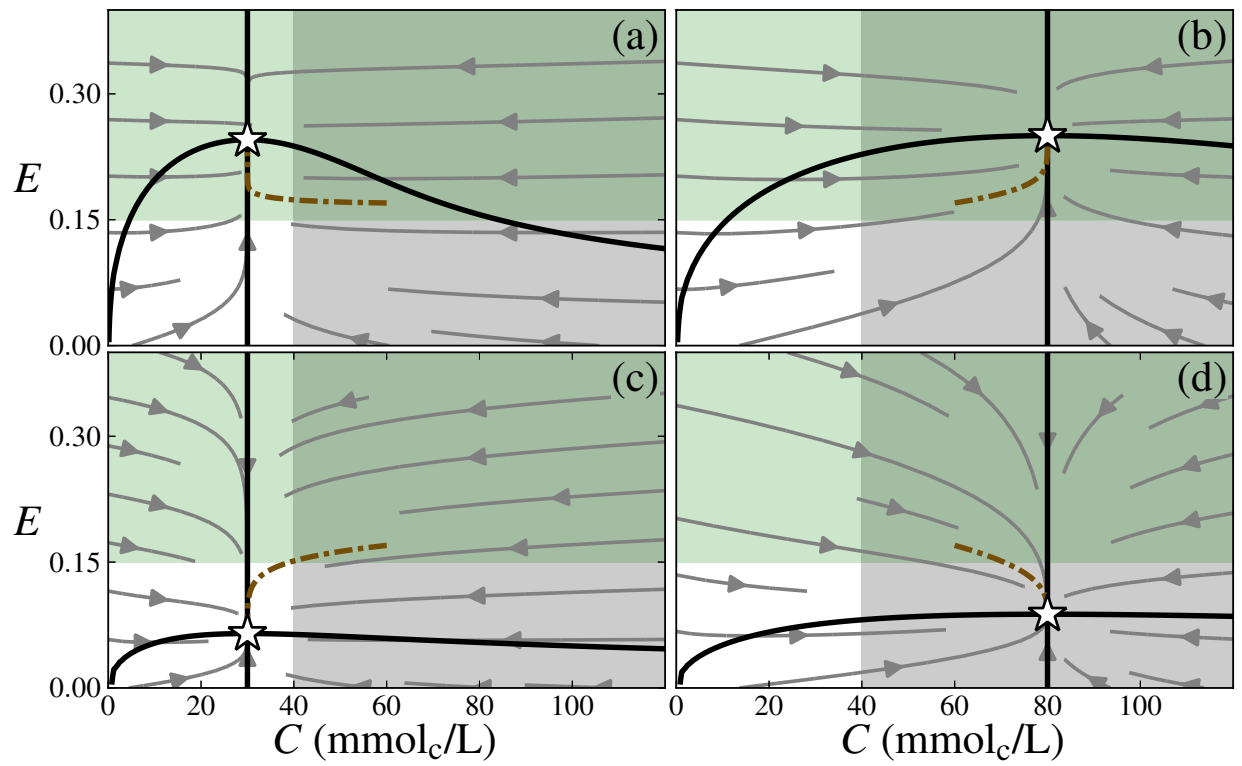

Figure 3: Phase-space dynamics of Eqs. (28). The stars indicate the steady-state solutions $S^{\star}$, the arrows denote the vector field of Eqs. (28), the solid black vertical line and solid black curves denote the nullclines of Eq. (28a) and (28b), respectively, and the brown dot-dashed orbits were calculated numerically, with initial conditions $C_{0}=60 \mathrm{mmol}_{\mathrm{c}} / \mathrm{L}$ and $E_{0}=0.17$. Each panel was calculated for a pair of the parameters $\left(C_{i}, E_{i}\right):$ Panel (a): (15,0.9); Panel (b): (40,0.8); Panel (c): $(15,0.45) ;$ Panel (d): $(40,0.4)$. For all panels $I=10 \mathrm{~mm} / \mathrm{d}, \mathrm{CEC}=100 \mathrm{mmol} / \mathrm{kg}$, $M=450 \mathrm{~kg} / \mathrm{m}^{2}$, and other parameters are as in Fig. 1.

\subsection{Phase-space analysis}

It does not seem possible to find an analytical solution $E(t)$ for Eq. (28b), as it was done for $C(t)[$ Eq. (8)]. Thus alternatively numerical solutions will be presented, using the standard Runge-Kutta method.

We divide the phase space in four quadrants, each representing a soil type: normal soil, $C<40, E<0.15$; saline soil, $C>40, E<0.15$; sodic soil, $C<40, E>0.15$; and saline-sodic soil, $C>40, E>0.15$, where $C$ is in $\mathrm{mmol}_{\mathrm{c}} / \mathrm{L}$.

Fig. 3 shows in gray streamplots of the vector field defined by Eqs. (28), for four pairs of parameters $\left(C_{i}, E_{i}\right)$ : each places the steady-state solution $S^{\star}=\left(C^{\star}, E^{\star}\right)$, marked with a star, in a different quadrant. The vertical solid black lines denote the nullcline of Eq. (28a), or $\mathrm{d} C / \mathrm{d} t=0$, while the solid black curves denote the nullcline of Eq. (28b), i.e. $\mathrm{d} E / \mathrm{d} t=0$. The graphic interpretation of the nullclines is that orbits in the phase space will move to the right (left) when the system is to the left (right) of the vertical solid black line. Likewise, the orbits move upwards (downwards) when the system is below (above) the solid black curve. For each of the four panels, we calculated numerically the trajectory in phase space of an orbit with initial conditions $C_{0}=60 \mathrm{mmol}_{\mathrm{c}} / \mathrm{L}$ and $E_{0}=0.17$, shown by the dot-dashed orbits.

The dynamics leading to the steady-state $S^{\star}$, defined by the meeting point of the nullclines, varies greatly depending on the parameters. In Fig. 3(d), for instance, the dot-dashed orbit indicates that a change in $E$ entails an accompanying change in $C$, while in Fig. 3(a) the dynamics is such that first $C$ reaches its steady-state value $C^{\star}$, and then the orbit approaches $S^{\star}$ by moving along the vertical nullcline $h_{1}=0$.

The temporal dynamics of the four simulated orbits in Fig. 3 is presented in the top panels of Fig. 4, in terms of the normalized distances

$$
x_{C}(t)=\left|\frac{C(t)-C^{\star}}{C_{0}-C^{\star}}\right|, \quad x_{E}(t)=\left|\frac{E(t)-E^{\star}}{E_{0}-E^{\star}}\right| .
$$

The normalized distances equal 1 at $t=0$ and go to zero as the variables $C, E$ approach their steady-state values. The full dark and dashed light curves represent $x_{C}$ and $x_{E}$, respectively. We find that $E$ always goes to its steadystate value over longer time scales than $C$, where the slowest convergence time scale is associated with a sodic soil [Fig. 4(a)], the fastest with a saline soil [Fig. 4(d)], and saline-sodic soil and normal soil (panels (b) and (c), respectively) have comparable time-scales.

A more precise evaluation of the time scales involved in the dynamics of $C$ and $E$ can be achieved by studying the eigenvalues $\sigma_{1}$ and $\sigma_{2}$. Eq. (34) shows the direct relation between $\sigma_{1}$ and the characteristic time scale $\tau_{C}$. Because Eq. (28a) for $C$ is linear, $\tau_{C}$ is a true measure of the time scale of the dynamics of $C$, independently of whether the initial condition $C_{0}$ is close or far from steady-state $C^{\star}$. However, since Eq. (28b) for $E$ is nonlinear, the eigenvalue $\sigma_{2}$ gives information on the characteristic time scale $\tau_{E}=$ $-1 / \sigma_{2}$ only in the vicinity of $S^{\star}$.

Fig. 4(e) shows the ratio $\sigma_{2} / \sigma_{1}$ in the parameter space comprised of the irrigation parameters $\left(C_{i}, E_{i}\right)$. A ratio smaller than 1 means that $\tau_{E}>\tau_{C}$, that is, in the vicinity of $S^{\star}$, it takes longer for $E$ to converge to $E^{\star}$ than for 


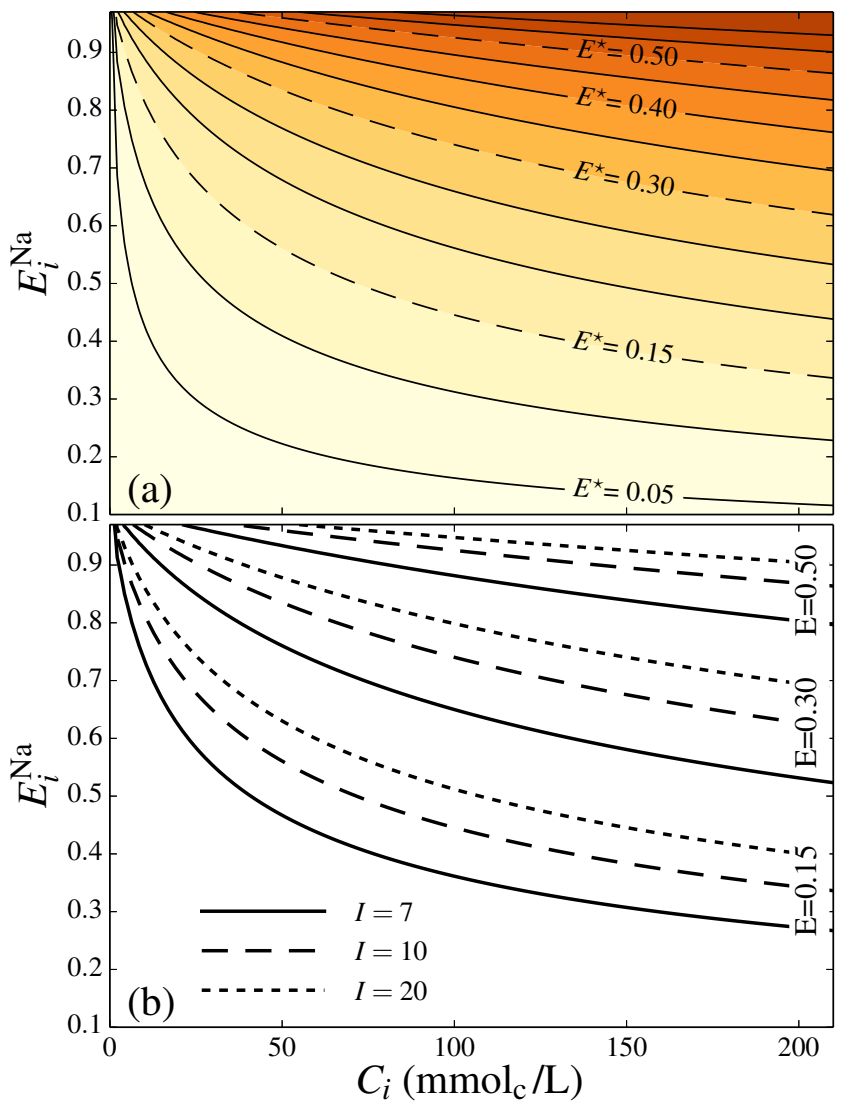

Figure 2: Steady-state soil sodicity $E^{\star}$ in the parameter space irrigation water concentration $C_{i}$ versus irrigation sodium fraction $E_{i}^{\mathrm{Na}}$. Panel (a): soil sodicity levels increase with $E_{i}^{\mathrm{Na}}$ and $C_{i}$. Dashed curves indicate sodicity boundary levels: $0.15,0.30$ and 0.50 . Irrigation rate: $I=10 \mathrm{~mm} /$ day. Panel (b): Critical sodicity boundaries for $I=7$ (solid lines), $I=10$ (long-dashed lines) and $I=20$ (shortdashed lines). Other parameters: same as in Fig. 1.

$C$ to converge to $C^{\star}$. Four points are labeled from a to $\mathrm{d}$, corresponding to the steady-state solutions in the four panels in Fig. 3. Points b and c have their ratio $\sigma_{2} / \sigma_{1}$ close to 0.2 , which means that for these two cases $E(t)$ approaches the steady-state about five times slower than $C(t)$.

One can fit an exponential curve to $E(t)$ in order to retrieve an approximate time scale of the dynamics, and check whether it conforms to $\tau_{E}$. An easier method is to calculate the ratio of the half-lives $t_{1 / 2}$ of $C(t)$ and $E(t)$, i.e., the time when the normalized distances $x_{C}$ and $x_{E}$ have decayed to 0.5 , and compare it to the ratio of the two eigenvalues. In the vicinity of the steady-state we expect to find that

$$
\frac{t_{1 / 2}(C)}{t_{1 / 2}(E)} \simeq \frac{\sigma_{2}}{\sigma_{1}} .
$$

Table 2 compares both ratios for the four cases a-d shown in Fig 4, whose initial condition was not in the vicinity of the steady state. Besides the coincidental excellent agreement in case d, the other cases have their ratios differing up to about $20 \%$. This means that $\sigma_{2}$ is able to provide
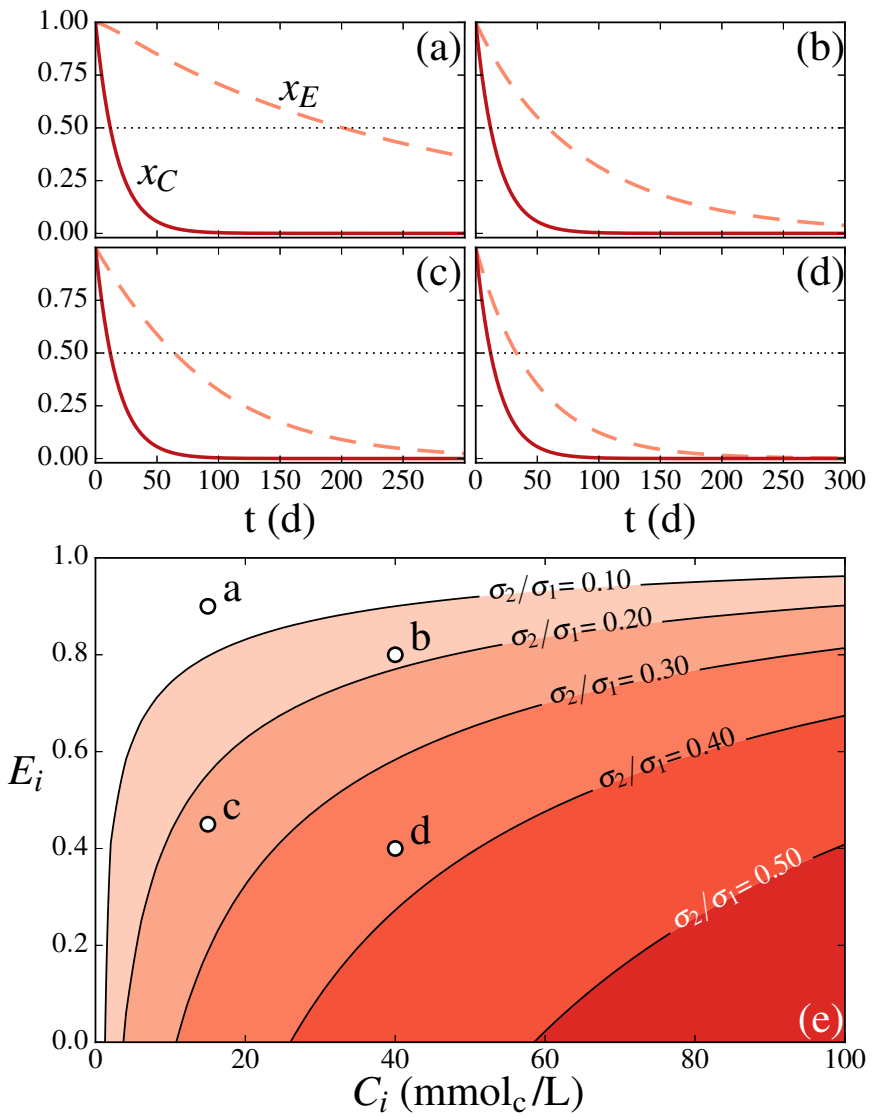

Figure 4: Panels (a)-(d): The normalized distances $x_{C}$ (dark curves) and $x_{E}$ (light dashed curves) as a function of time, for the dotdashed numerical orbits also shown in Fig. 3. Panel (e): the ratio of eigenvalues $\sigma_{2} / \sigma_{1}$ in the parameter space $\left(C_{i}, E_{i}\right)$. The white circles correspond to the values of $C_{i}$ and $E_{i}$ in the four panels of Fig. 3 . For all panels $I=10 \mathrm{~mm} / \mathrm{d}, \mathrm{CEC}=100 \mathrm{mmol}_{\mathrm{c}} / \mathrm{kg}, M=450 \mathrm{~kg} / \mathrm{m}^{2}$, and other parameters are as in Fig. 1.

rough estimates of typical time scales of soil salinization, sodification, as well as their reclamation, even though it is strictly valid only in the phase space near $S^{\star}$.

Table 2: Comparison table of the half-life ratios and eigenvalues ratios shown in Eq. (36), for the four cases a-d discussed in the top panels of Fig. 4.

\begin{tabular}{l|cccc} 
& & & \\
measure & case & (b) & (c) & (d) \\
\hline$t_{1 / 2}(C) / t_{1 / 2}(E)$ & 0.060 & 0.201 & 0.188 & 0.366 \\
\hline$\sigma_{2} / \sigma_{1}$ & 0.049 & 0.180 & 0.234 & 0.366
\end{tabular}

In Appendix $\mathrm{C}$ we compare both the Gapon and Vanselow approaches with regard to phase-space dynamics and typical time scales of convergence.

\section{Conclusions}

We presented here a simple system of differential equations to describe the dynamics of soil salinity and sodicity. 
One main result is the determination of time scales for the convergence of $C$ and $E$ to their steady-state values. The time scale $\tau_{C}$ associated with the dynamics of soil salinity is a function only of the ratio between the soil water content $w^{\star}$ and the percolation rate $L^{\star}$ : higher irrigation rates imply higher percolation rates, which in turn mean shorter convergence times $\tau_{C}$. We could also establish that the eigenvalue $\sigma_{2}$, associated with the dynamics of $E$ in the vicinity of the steady state $E^{\star}$, gives a rough estimate of convergence times of soil sodicity, even when initial conditions are far from $E^{\star}$.

The phase portraits in Fig. 3 show the different kinds of trajectories prescribed by the system's equations. One can control irrigation parameters $C_{i}, E_{i}$ and $I$ when managing salinity and sodicity, so orbits stay in desired boundaries in the phase space, or so they evolve in a timely manner. For instance, when reclaiming a sodic soil, a judicious timedependent addition of calcium cations to irrigation water can minimize reclamation times while keeping calcium additives in amounts that are economical.

We also investigated in Appendix $\mathrm{C}$ the effects of different choices of exchange reaction equations on the dynamics of $C$ and $E$ and steady-state solutions. We found that the Gapon and Vanselow equations give very similar results with regard to the location of the steady state in the phase space, to the orbit leading to the steady state, and to the typical times associated with convergence of $E$.

Some of the approximating assumptions here can be refined, in order to produce a more realistic model. Salinity and sodicity levels can influence greatly hydraulic conductivity and infiltration rates [25]. By introducing a dependence of $K_{s}$ on $C$ and $E$ (e.g. [26, 27]) this effect can be included by allowing the soil water $w$ to become a dynamical variable, with its own equation coupled to that of $C$ and $E$. This would also allow us to investigate the effect of various irrigation strategies (e.g., micro-irrigation, traditional irrigation) on salt leaching and on avoiding crop water stress.

A further modification could be the introduction of precipitation by a stochastic process with seasonally varying parameters, to study the role of off-growing-season rain events in leaching salts, as well as long-term climatic effects on soil salinity and sodicity. Finally, this root zone averaged model presented here can be coupled to the ground water, in order to allow for the capillary rise of saline water from deeper layers, which in some areas is a major contributing factor in secondary salinization. These extensions will be addressed in future studies.

\section{Acknowledgements}

The authors would like to thank SEATM van der Zee for useful discussion. YM acknowledges support from BARD, the United States-Israel Binational Agricultural Research and Development Fund, Vaadia-BARD Postdoctoral Fellowship Award No FI-517-14. AP acknowledges NSF Grants: CBET 1033467, EAR 1331846, EAR 1316258, FESD 1338694, as well as the US DOE through the Office of Biological and Environmental Research, Terrestrial Carbon Processes program (de-sc0006967), the Agriculture and Food Research Initiative from the USDA National Institute of Food and Agriculture (2011-67003-30222).

\section{Appendix A. Expressions derived from the Gapon Equation}

By manipulating the Gapon Equation (16) one can derive common expressions found in the literature of soil salinity and sodicity.

First, substituting Eq. (17a) into Eq. (16) yields

$$
\mathrm{SAR}=\frac{1}{K_{g}} \frac{\mathrm{ESP} / 100}{1-\mathrm{ESP} / 100}
$$

Fig. A.5(a) shows in dark blue a plot of Eq. (A.1), and the black dashed line represents the curve SAR $=$ ESP. The numerical value of ESP and SAR is approximately equal for ESP $<40$, which justifies the common interchangeability of the terms in discussions on soil sodicity. However, note that SAR diverges when ESP $\rightarrow 100 \%$.

An equation for the equivalent fractions is obtained by substituting Eqs. (17) into Eq. (16), and using [Na] $=C E_{s}^{\mathrm{Na}}$ and $[\mathrm{Ca}]=C\left(1-E_{s}^{\mathrm{Na}}\right)$ :

$$
\frac{E_{x}^{\mathrm{Na}}}{1-E_{x}^{\mathrm{Na}}}=K_{g} \sqrt{2 C} \frac{E_{s}^{\mathrm{Na}}}{\sqrt{1-E_{s}^{\mathrm{Na}}}} .
$$

Eq. (A.2) solved for $E_{x}^{\mathrm{Na}}$ finally yields

$$
\begin{aligned}
E_{x}^{\mathrm{Na}} & =g_{x}\left(C, E_{s}^{\mathrm{Na}}\right) \\
& =\left(1+\sqrt{\frac{1-E_{s}^{\mathrm{Na}}}{2 C}} \frac{1}{K_{g} E_{s}^{\mathrm{Na}}}\right)^{-1} .
\end{aligned}
$$

Eq. (A.3) is the exchange isotherm, which describes the dependence of $E_{x}^{\mathrm{Na}}$ on $E_{s}^{\mathrm{Na}}$ and $C$. It is plotted in dark blue in Fig. A.5(b), for two soil water concentration values. Higher electrolyte concentrations result in higher sodium equivalent fractions in the exchange complex, for the whole range of $E_{s}^{\mathrm{Na}}$.

\section{Appendix B. Gapon and Vanselow conventions}

The discussion below is based on a paper by Sposito [28], to which the reader is referred for a more detailed analysis.

The Gapon and the Vanselow conventions differ in how they choose to account for the exchange reactants. The Vanselow convention chooses the cations $\mathrm{Na}^{+}$and $\mathrm{Ca}^{2+}$ to react in molar amounts, leading to the exchange reaction

$$
\mathrm{CaX}_{2}+2 \mathrm{Na}^{+}=\mathrm{Ca}^{2+}+2 \mathrm{NaX}
$$



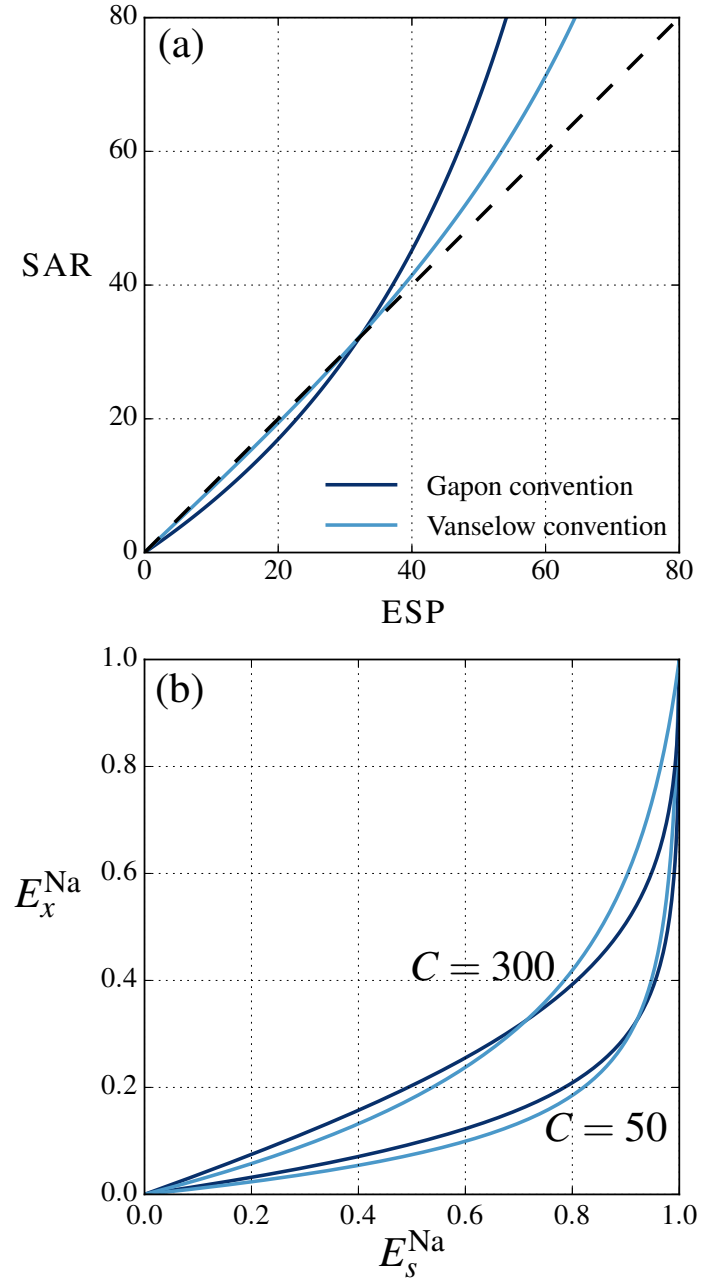

Figure A.5: (a): The nonlinear relationship between the sodium adsorption ratio (SAR) and the exchangeable sodium percentage (ESP), as described by the Gapon convention (Eq. (A.1) in dark blue) and by the Vanselow convention (Eq. (B.8) in light blue). The black dashed line denotes the identity SAR $=$ ESP. (b): Exchange isotherm defined by the Gapon Eq. (A.2) (in dark blue) and by the Vanselow Eq. (B.7) (in light blue), for two salt concentration values: 50 and $300 \mathrm{mmol}_{\mathrm{C}} / \mathrm{L}$.

where the exchanger $\mathrm{X}$ has charge $1-$. Conversely, the Gapon convention chooses the reaction to be in moles of charge, giving

$$
2 \mathrm{Ca}_{1 / 2} \mathrm{X}+2 \mathrm{Na}^{+}=\mathrm{Ca}^{2+}+2 \mathrm{NaX} .
$$

The notation $\mathrm{Ca}_{1 / 2} \mathrm{X}$ should be understood as one mole of charge of calcium adsorbed to one mole of charge of the exchanger. Both conventions are equal macroscopically with regard to mass and charge conservation, but in the microscopic level, there is no correspondent to $\mathrm{Ca}_{1 / 2} \mathrm{X}$, because there cannot be half a $\mathrm{Ca}^{2+}$ ion. So in this respect Eq. (B.1) should be preferred. Each convention prescribes different equations for the selectivity coefficients of the re- action:

$$
\begin{aligned}
& \text { Gapon : } K_{g}=\frac{\left[\mathrm{Ca}^{2+}\right]^{1 / 2} E_{x}^{\mathrm{Na}}}{\left[\mathrm{Na}^{+}\right] E_{x}^{\mathrm{Ca}_{1 / 2}}} \\
& \text { Vanselow : } \quad K_{v}=\frac{\left[\mathrm{Ca}^{2+}\right]^{1 / 2} \chi_{x}^{\mathrm{Na}}}{\left[\mathrm{Na}^{+}\right]\left(\chi_{x}^{\mathrm{Ca}}\right)^{1 / 2}},
\end{aligned}
$$

where the square brackets denote molar concentration of the ion in the solution, $E$ is the equivalent fraction, and $\chi$ is the mole fraction. In this paper, the quantity $E_{x}^{\mathrm{Ca}_{1 / 2}}$ is written simply as $E_{x}^{\mathrm{Ca}}$.

Substituting

$$
\left[\mathrm{Ca}^{2+}\right]=\frac{C E_{s}^{\mathrm{Ca}}}{2}, \quad\left[\mathrm{Na}^{+}\right]=C E_{s}^{\mathrm{Na}}
$$

into Eq. (B.3a) and rearranging the terms, one arrives at the Gapon Eq. (A.2).

Sposito discusses the thermodynamic assumptions and implications related to each convention, and gives a corrected form of Eq. (A.2), derived from the Vanselow Eq. (B.3b). Using the fact that the molar fractions read

$$
\chi_{x}^{\mathrm{Na}}=\frac{[\mathrm{NaX}]}{[\mathrm{NaX}]+\left[\mathrm{CaX}_{2}\right]}, \quad \chi_{x}^{\mathrm{Ca}}=\frac{\left[\mathrm{CaX}_{2}\right]}{[\mathrm{NaX}]+\left[\mathrm{CaX}_{2}\right]}
$$

and that the molar concentrations in the exchange complex read

$$
[\mathrm{NaX}]=\operatorname{CEC} E_{x}^{\mathrm{Na}}, \quad\left[\mathrm{CaX}_{2}\right]=\frac{\mathrm{CEC} E_{x}^{\mathrm{Ca}}}{2},
$$

one can substitute Eqs. (B.5) and (B.6) into Eq. (B.3b), to achieve, after some algebra, the Vanselow equation

$$
\frac{E_{x}^{\mathrm{Na}}}{\sqrt{1-\left(E_{x}^{\mathrm{Na}}\right)^{2}}}=\frac{K_{v}}{2} \sqrt{2 C} \frac{E_{s}^{\mathrm{Na}}}{\sqrt{1-E_{s}^{\mathrm{Na}}}} .
$$

The Vanselow selectivity coefficient $K_{v}$ was calculated [29] for the same 59 soil samples reported by the United States Salinity Laboratory [15] as $K_{v}=0.02105$. Note that Oster and Sposito [29] present a different version of Eq. (B.7), whose selectivity coefficient equals $47.5 . K_{v}$ as reported in this paper reads $K_{v}=1 / 47.5$.

Substituting $E_{x}^{\mathrm{Na}}=\mathrm{ESR} /(1+\mathrm{ESR})$ into the left-hand side of Eq. (B.7), and writing its right-hand side as $K_{v} \mathrm{SAR} / 2$, leads to

$$
\mathrm{SAR}=\frac{2}{K_{v}} \frac{\mathrm{ESP} / 100}{\sqrt{1-(\mathrm{ESP} / 100)^{2}}},
$$

which is plotted in light blue in Fig. A.5(a), alongside the dark blue curve, representing Eq. (A.1). For the whole range of ESP, the Vanselow-derived relation above is closer to the identity SAR = ESP than the Gapon-derived relation.

As discussed by Oster and Sposito [29] and attested by Fig. A.5, the empirical Gapon equation and the Vanselow equation are effectively indistinguishable in an ESP range of practical significance. 
Solving Eq. (B.7) for $E_{x}^{\mathrm{Na}}$ and $E_{s}^{\mathrm{Na}}$ yields

$$
\begin{aligned}
E_{x}^{\mathrm{Na}} & =v_{x}\left(C, E_{s}^{\mathrm{Na}}\right) \\
& =\left[1+\frac{2\left(1-E_{s}^{\mathrm{Na}}\right)}{C\left(E_{s}^{\mathrm{Na}} K_{v}\right)^{2}}\right]^{-1 / 2} \\
E_{s}^{\mathrm{Na}} & =v_{s}\left(C, E_{x}^{\mathrm{Na}}\right) \\
& =\frac{2}{1+\sqrt{1+2 K_{v}^{2} C\left(1-\frac{1}{\left(E_{x}^{\mathrm{Na}}\right)^{2}}\right)}} .
\end{aligned}
$$

where $v_{x}$ gives a different exchange isotherm than $g_{x}$. The Vanselow exchange isotherm $v_{x}$ is plotted in light blue in Fig. A.5(b), alongside $g_{x}$ in dark blue.

The dynamical equation for the equivalent fraction of sodium in the exchange complex $E_{x}^{\mathrm{Na}}$ (also called here simply $E$ ) can be based in the Vanselow interpretation instead of Gapon's, as was done in Sec. 3. We can do so simply by substituting $g_{s}(C, E)$ for $v_{s}(C, E)$ in Eqs. (26), where the partial derivatives now read

$$
\begin{aligned}
& \frac{\partial v_{s}(C, E)}{\partial C}=-\frac{\left(1-\frac{1}{E^{2}}\right) K_{v}^{2} v_{s}^{3}}{2\left(2-v_{s}\right)} \\
& \frac{\partial v_{s}(C, E)}{\partial E}=-\frac{C K_{v}^{2} v_{s}^{3}}{E^{3}\left(2-v_{s}\right)} .
\end{aligned}
$$

\section{Appendix C. Effect of exchange reaction conven- tion on dynamics}

We investigate here the role of Gapon's and Vanselow's conventions on the coupled dynamics of soil salinity and sodicity. Fig. C.6 shows two trajectories in the phase space $(C, E)$, both beginning at $(20.0,0.30)$, i.e., in a sodic soil state. The irrigation rate is $I=10 \mathrm{~mm} / \mathrm{d}$, and irrigation water quality is $C_{i}=40 \mathrm{mmol}_{\mathrm{c}} / \mathrm{L}$ and $E_{i}=0.40$, which according to Figs. 1 and 2 places the steady state in the quadrant corresponding to a saline soil. The darker trajectory marked with G was calculated using the Gaponderived function $g_{s}$ and its partial derivatives in Eq. (25). Likewise, the lighter trajectory marked with $\mathrm{V}$ used the Vanselow-derived function $v_{s}$ and its partial derivatives.

Most markedly, the steady state of trajectories G and $\mathrm{V}$, indicated with a circle and a diamond, respectively, have the same salinity level $C^{\star}$, but their sodicity level $E^{\star}$ do not coincide. This stems from the fact that the dynamics of $C$, governed by Eq. (7), is unaffected by our choice of interpretation of the exchange reaction, and that the exchange isotherms $g_{x}$ and $v_{x}$ do prescribe different values of $E$ for same salt concentrations and same values of $E_{s}^{\mathrm{Na}}$, as shown in Fig. A.5(b).

The inset in Fig. C.6 shows the evolution of $E$ in time for both trajectories $G$ and $V$. Although the two curves level off at different values of $E$, they do so in similar time scales. The time it takes for $G$ and $V$ to cross the sodicity threshold $E=0.15$, marked by a dotted line in the inset, is 61 and 51 days, respectively. From this example and

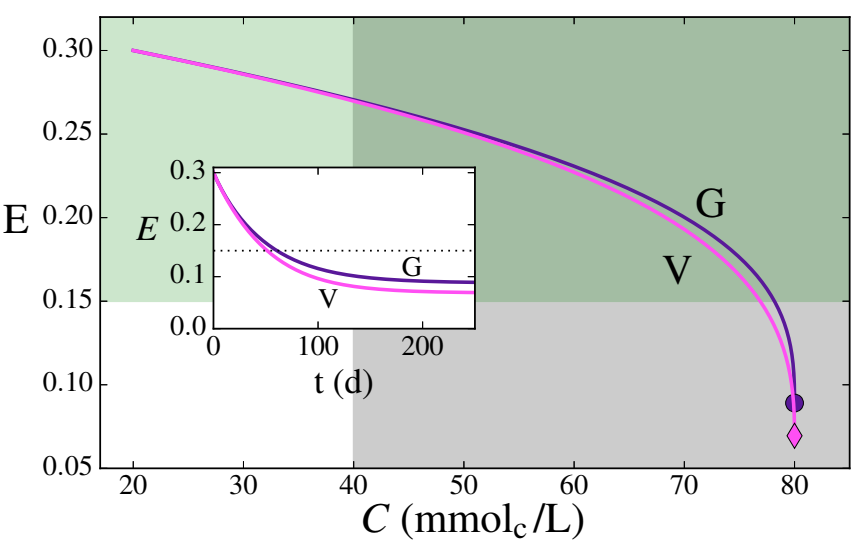

Figure C.6: Trajectories in the phase space $(C, E)$ calculated using the Gapon $(\mathrm{G})$ and the Vanselow $(\mathrm{V})$ conventions for the exchange reaction of $\mathrm{Na}$ and $\mathrm{Ca}$. The initial condition for both curves is $(20.0,0.30)$. Inset: Evolution of $E$ in time for the same trajectories. Parameters: $C_{i}=40 \mathrm{mmol}_{\mathrm{c}} / \mathrm{L}, E_{i}=0.40, I=10 \mathrm{~mm} / \mathrm{d}$, $\mathrm{CEC}=100 \mathrm{mmol}_{\mathrm{c}} / \mathrm{kg}, M=450 \mathrm{~kg} / \mathrm{m}^{2}$, and other parameters as in Fig. 1.

other cases not shown here, we conclude that both Gapon and Vanselow conventions yield dynamical results that are qualitatively very similar.

[1] E. V. Maas, Salt tolerance of plants, Handbook of plant science in agriculture 2 (1984) 57-75.

[2] I. P. Abrol, J. S. P. Yadav, F. I. Massoud, Salt-affected soils and their management, no. 39 in FAO soils bulletin, Food \& Agriculture Org., 1988

[3] L. Bernstein, Effects of salinity and sodicity on plant growth, Annual review of phytopathology 13 (1) (1975) 295-312.

[4] G. J. Levy, Sodicity, in: P. M. Huang, Y. Li, M. E. Sumner (Eds.), Handbook of soil sciences: resource management and environmental impacts, 2nd Edition, CRC Press, 2012, Ch. 18.

[5] F. Ghassemi, A. J. Jakeman, H. A. Nix, et al., Salinisation of land and water resources: human causes, extent, management and case studies., Cab International, 1995.

[6] H. Bekle, J. Mulcock, H. Phillips, The salinity crisis: landscapes, communities and politics, UWA Publishing, 2004.

[7] J. Šimunek, D. L. Suarez, Sodic soil reclamation using multicomponent transport modeling, Journal of irrigation and drainage engineering 123 (5) (1997) 367-376.

[8] D. L. Suarez, Sodic soil reclamation: Modelling and field study, Soil Research 39 (6) (2001) 1225-1246.

[9] S. Suweis, A. Rinaldo, S. E. A. T. M. van der Zee, E. Daly, A. Maritan, A. Porporato, Stochastic modeling of soil salinity, Geophysical Research Letters 37 (7).

[10] Y. Mau, X. Feng, A. Porporato, Multiplicative jump processes and applications to leaching of salt and contaminants in the soil, Physical Review E 90 (5) (2014) 052128.

[11] S. E. A. T. M. van der Zee, S. Shah, R. Vervoort, Root zone salinity and sodicity under seasonal rainfall due to feedback of decreasing hydraulic conductivity, Water Resources Research.

[12] I. Rodríguez-Iturbe, A. Porporato, Ecohydrology of watercontrolled ecosystems: soil moisture and plant dynamics, Cambridge University Press, 2004.

[13] G. Vico, A. Porporato, From rainfed agriculture to stressavoidance irrigation: Ii. sustainability, crop yield, and profitability, Advances in Water Resources 34 (2) (2011) 272-281.

[14] G. S. Campbell, A simple method for determining unsaturated conductivity from moisture retention data., Soil Science 117 (6) (1974) 311-314.

[15] L. A. Richards, Diagnosis and improvement of saline and alkali soils., Soil Science 78 (2) (1954) 154. 
1 [16] G. Sposito, The Chemistry of Soils, Oxford University Press, USA, 2008.

[17] D. S. Orlov, Soil Chemistry: Russian Translation, AA Balkema Publishers, 1992.

[18] G. Sposito, et al., The Thermodynamics of Soil Solutions., Oxford University Press., 1981.

[19] D. Suarez, J. Jurinak, The chemistry of salt-affected soils and waters, in: W. W. Wallender, K. K. Tanji (Eds.), Agricultural Salinity Assessment and Management, 2nd Edition, American Society of Civil Engineers, 2011, Ch. 3, pp. 57-88.

[20] G. Sposito, S. V. Mattigod, On the chemical foundation of the sodium adsorption ratio, Soil Science Society of America Journal 41 (2) (1977) 323-329.

[21] R. Levy, E. Mor, Soluble and exchangeable cation ratios in some soils of Israel, Journal of Soil Science 16 (2) (1965) 290-295.

[22] A. Meiri, R. Levy, Evaluation of salinity in soils and plants, in Arid Zone Irrigation, Springer, 1973, pp. 291-299.

[23] M. Agassi, I. Shainberg, J. Morin, Effect of electrolyte concentration and soil sodicity on infiltration rate and crust formation, Soil Science Society of America Journal 45 (5) (1981) 848-851.

[24] G. J. Levy, D. Goldstein, A. I. Mamedov, Saturated hydraulic conductivity of semiarid soils: Combined effects of salinity, sodicity, and rate of wetting, Soil Science Society of America Journal 69 (3) (2005) 653-662.

[25] I. Shainberg, M. Singer, Soil response to saline and sodic conditions, in: W. W. Wallender, K. K. Tanji (Eds.), Agricultural Salinity Assessment and Management, 2nd Edition, American Society of Civil Engineers, 2011, Ch. 5, pp. 139-167.

[26] B. L. McNeal, Prediction of the effect of mixed-salt solutions on soil hydraulic conductivity, Soil Science Society of America Journal 32 (2) (1968) 190-193.

27] Y. D. Ezlit, J. M. Bennett, S. R. Raine, R. J. Smith, Modification of the mcneal clay swelling model improves prediction of saturated hydraulic conductivity as a function of applied water quality, Soil Science Society of America Journal 77 (6) (2013) 2149-2156.

28] G. Sposito, The gapon and the vanselow selectivity coefficients, Soil Science Society of America Journal 41 (6) (1977) 1205-1206.

[29] J. D. Oster, G. Sposito, The gapon coefficient and the exchangeable sodium percentage-sodium adsorption ratio relation, Soil Science Society of America Journal 44 (2) (1980) 258-260. 